\title{
Glacial rumblings from Jakobshavn ice stream, Greenland
}

\author{
J.A. RIAL, ${ }^{1}$ C. TANG $^{1}$ K. STEFFEN ${ }^{2}$ \\ ${ }^{1}$ Department of Geological Sciences, University of North Carolina, Chapel Hill, North Carolina 27599-3315, USA \\ E-mail: jar@email.unc.edu \\ ${ }^{2}$ Cooperative Institute for Research in Environmental Studies (CIRES), University of Colorado, Boulder, Colorado 80309-0216,
} USA

\begin{abstract}
The steep increase in Greenland's glacial earthquake activity detected by the Global Seismographic Network since the late 1990s suggests that a close inspection of these events might provide clues to the nature and origin of such seismic activity. Here we discuss the detection of large, unexpected seismic events of extraordinarily long duration $(\mathbf{1 0}-40 \mathrm{~min})$ occurring about once every 2 days, and localized in the ice stream that feeds the Earth's fastest-moving glacier (Jakobshavn Isbræ) from the east. These 'glacial rumblings' represent an ice-mass wasting process that is greater and more frequent than glacial earthquakes have suggested. Probably triggered by calving, the rumblings are all very similar regardless of duration, and all end with a sharp, earthquake-like event in which the largest seismic amplitude is in the rumbling and that might signal the collapse of large ice masses upstream. By calculating the total amount of seismic energy released as rumblings, we estimate that the maximum seasonal amount of ice moved seismogenically down the ice stream is up to $12 \mathrm{~km}^{3}$, or $\sim 30 \%$ of the average annual iceberg discharge in Jakobshavn.
\end{abstract}

\section{INTRODUCTION}

The largest outlet glaciers of the Greenland ice sheet (GIS) have suffered rapid and dramatic changes during the last few years. As the climate warms, GIS glaciers have lost kilometres of ice at their calving fronts (Joughin and others, 2004; Howat and others, 2005), thinned by $15 \%$ or more in their lower reaches (Alley and others, 2007; Howat and others, 2007; Stearns and Hamilton, 2007) and accelerated by factors of 1.5-2 (Howat and others, 2005; Rignot and Kanagaratnam, 2006). Surface melting has steadily increased (Steffen and Huff, 2005; Steffen and others, 2006), resulting in the seasonal delivery of lubricating meltwater to the base of the ice sheet (Zwally and others, 2002; Steffen and others, 2004). Meanwhile, the Global Seismographic Network (GSN) detected a steep increase in seismic activity around the outlet glaciers (Ekström and others, 2003). These findings are consistent with the idea that ice sheets can respond rapidly and even catastrophically to external forcing (Hansen, 2005; Bamber and others, 2007), but the physical processes involved remain poorly understood. In fact, little is known about the causes of glacial earthquakes, a term used to describe what might be bulk ice motions responding to global warming (Ekström and others, 2003). Based on teleseismic recordings by the GSN, glacial earthquakes are described as being produced by large ice slides, and are quantified by a product of mass and sliding distance of the order of $0.1-2.0 \times 10^{14} \mathrm{~kg} \mathrm{~m}^{-1}$. This is equivalent to $1-20 \mathrm{~km}^{3}$ blocks of ice sliding $10 \mathrm{~m}$ in about $50 \mathrm{~s}$, resulting in surfacewave magnitudes of 4.6-5.1 (Tsai and Ekström, 2007).

\section{RUMBLINGS AND GLACIAL EARTHQUAKES}

To study glacial earthquakes more closely, we deployed a ten-station, short-period, three-component portable IRIS (Incorporated Research Institutions for Seismology)/PASSCAL (Program for the Array Seismic Studies of the Continental Lithosphere) seismic array codenamed SMOGIS (Seismic Monitoring of Greenland's Ice Sheet), near Swiss Camp,
$50 \mathrm{~km}$ north of Jakobshavn Isbræ, one of the areas identified as generating glacial earthquakes (Tsai and Ekström, 2007). Jakobshavn is the fastest-moving glacier in the world, responsible for nearly $7 \%$ of Greenland's annual ice loss, and fed from the north and the east by two major ice streams (Joughin and others, 2004). The seismic deployment recorded continuously for 96 days during the 2006 field season (May-August; a smaller but wider four-sensor array was deployed during May-August 2007) and detected a number of different types of seismic event, including some likely to have been produced by thermal cracking, crevassing and basal sliding of the ice sheet. Also detected were over 40 long-lasting, distinctive seismic events that we named rumblings (or glacial rumbles). These have been tentatively classified as a class of glacial earthquake; they are the largest and longest-lasting seismic events in the monitored area and are characterized by tremors lasting 10-40 min (Fig. 1) occurring about once every 2 days during the melt season. Apparently triggered by calving at the glacier's front, the rumblings eventually end in a major earthquake-like shear rupture that we call the culminating event (Fig. 1). Regardless of their duration, all rumblings produce remarkably similar seismograms from beginning to end (Fig. 1). To estimate the location of rumblings we used ordinary seismic events (with $\mathrm{P}$ - and S-wave radiation) embedded in and clearly related to them (Fig. 2). The strongest (and easiest to locate) of these are the culminating events, the radiation patterns of which are consistent with those of a shear rupture along a fault plane, just like ordinary earthquakes. That is, their radiation pattern characteristics are consistent with those of a shear rupture along a fault plane, a source mechanism typical of ordinary earthquakes (Fig. 3). The most accurately located events cluster around a major bend in the northern margin of the ice stream, 5-11 km upstream from the calving front, and show very clear $\mathrm{P}$ - and S-wave arrivals with moment magnitudes, $M_{\mathrm{W}}$, ranging from 4 to 4.3 , smaller than the low-end value calculated with the GSN. We return to this important point in the Discussion section. 

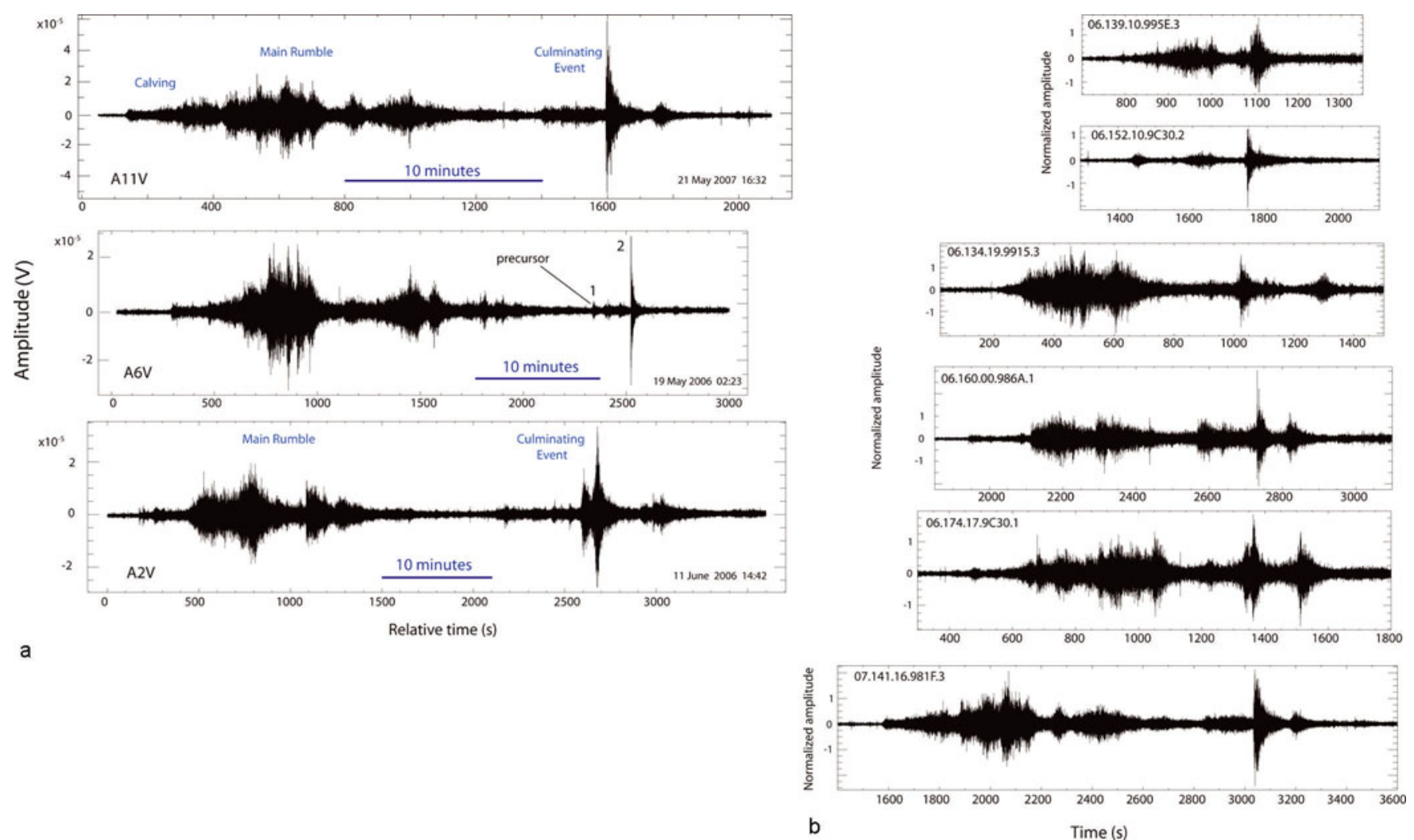

Fig. 1. (a) Examples of a new class of seismic source on Greenland: glacial rumblings from the Jakobshavn area. Over 40 such rumblings were recorded in 96 days of continuous recording. Vertical components of ground motion are shown recorded on different dates at three stations of the seismic array. The events are remarkably similar from beginning to end. The rumble of 19 May 2006 shows a clear precursor (labeled 1) to the culminating event (2). The epicentral locations of these events suggest upstream propagation of the seismogenic rupture process (see text for details). (b) Further examples of rumblings detected at all the recording stations of the seismic array. Notice the similarity among all seismograms regardless of their very different durations $(10-35 \mathrm{~min})$. The culminating event has the largest amplitude in all sequences and can be followed closely by a smaller 'aftershock'.

Because of the limitations of recording with the detail afforded to a local seismic survey, the GSN detected only a few of the rumblings reported here, and not as long-lasting rumblings but rather as discrete glacial earthquakes, some of which we identify with the culminating seismic events mentioned above. Figure 4 illustrates the relationship between glacial earthquakes and rumblings. What we describe as a rumbling is recorded by the GSN as multiple and not necessarily, or obviously, connected seismic events. The high-frequency detail recorded by the SMOGIS array, which was lost to the GSN detectors, reveals a number of characteristics of glacial earthquakes that have not been observed before.

\section{Hypocenter locations}

Seismic events are located using a standard iterative nonlinear inverting algorithm based on Geiger's method (Lee and Stewart, 1981) to determine the origin time and hypocenter of an earthquake from P-wave arrival times. In most cases, as the iteration proceeds, the solution vector (three spatial coordinates and time) will converge until the error is within some preset tolerance (based on data quality, this can vary slightly from station to station). If, in addition to P-wave arrival times, S-wave arrival times are used, the inversion scheme is better constrained. As the rumblings are all outside the area covered by the array, hypocentral locations using only P-wave readings occasionally give less reliable results. Accordingly, we used both P- and S-wave arrival times when possible. Resulting errors in location are shown in Table 1 to range between 1 and $2 \mathrm{~km}$ horizontally for the best-located earthquakes and up to $7 \mathrm{~km}$ horizontally for the less well located (Fig. 2). These standard formal errors are extracted from the error matrix of the inversion procedure (e.g. Lawson and Hanson, 1995). The focal depth is unconstrained but has been estimated as $1.5-2.0 \mathrm{~km}$ using synthetic seismograms (see below). Particle motions at each station were also used to confirm the general direction of approach of the seismic waves to the receivers. Typical S-P times to the receivers are $6-7.5 \mathrm{~s}$, which corresponds to epicentral distances of $48-58 \mathrm{~km}$ from the array. The onedimensional (1-D) seismic velocity model used is a layer of ice $1.2 \mathrm{~km}$ thick (a thickness range of $0.9-1.5 \mathrm{~km}$ did not produce a notable difference in the resulting seismograms) overlying a rock half-space. The average P-wave velocity in the ice of $3.6 \mathrm{~km} \mathrm{~s}^{-1}$ is estimated from observations of Pwaves from near earthquakes. The average S-wave velocity in the ice is estimated at $1.8 \mathrm{~km} \mathrm{~s}^{-1}$. The rock underneath the ice sheet has a P-wave velocity of $6.1 \mathrm{~km} \mathrm{~s}^{-1}$, estimated from surface-wave dispersion detected by the array. A smooth, positive velocity gradient of $1 \%$ in $10 \mathrm{~km}$ was used in the lower layer to account for strong amplitudes of P-waves at the stations. As described later, the ice sheet between Swiss Camp and Jakobshavn forms an excellent resonating seismic wave-guide the estimated average thickness and shear wave velocity of which are consistent with the velocity model. In fact, the clear resonance shown 


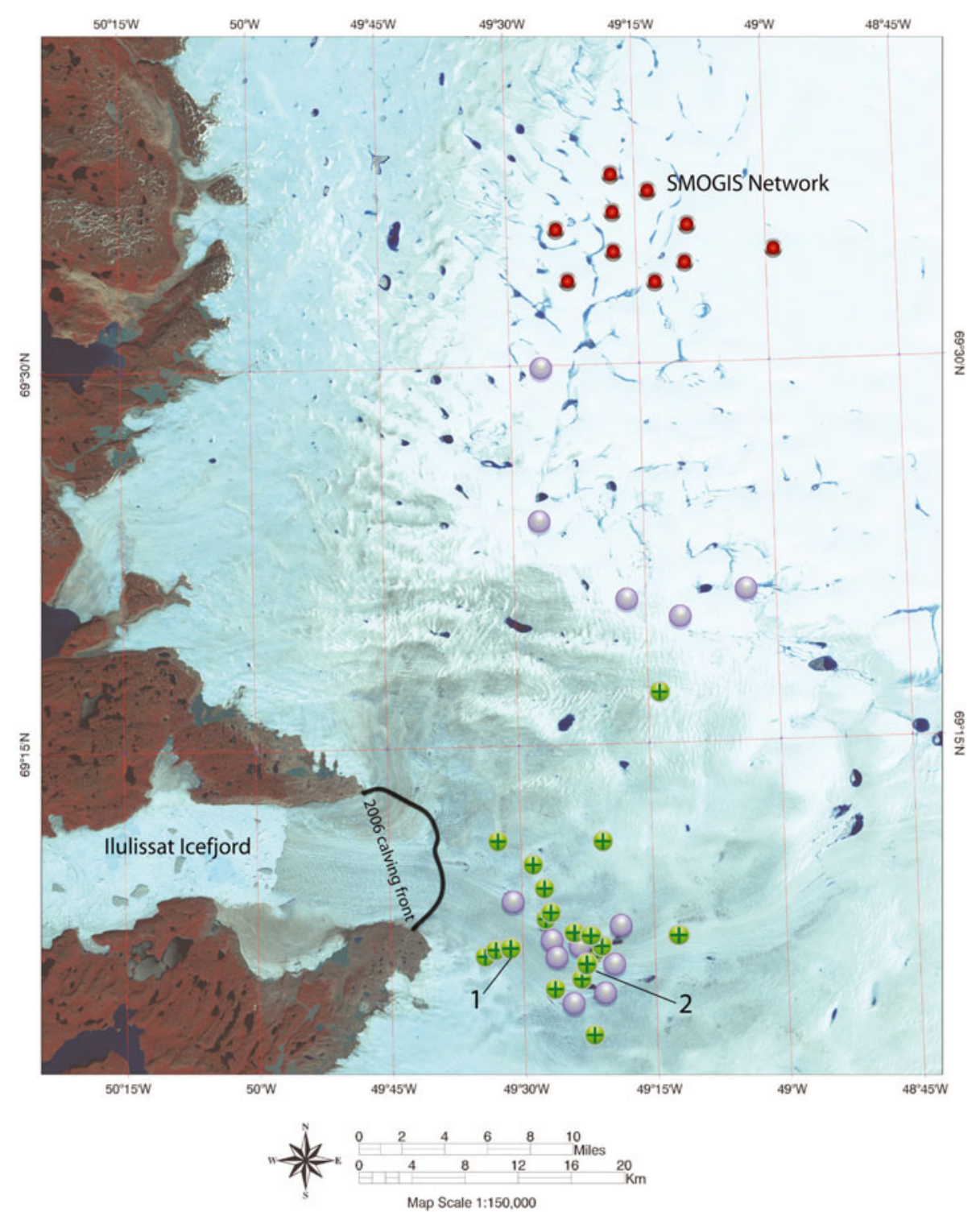

Fig. 2. Epicenters of glacial seismogenic events in the neighborhood of Jakobshavn glacier. Green circles with a plus sign: location error no greater than $2 \mathrm{~km}$. Gray circles: location error greater than $2 \mathrm{~km}$ but less than $7 \mathrm{~km}$. Most events occur along the margin of the ice stream that feeds the glacier from the east. No seismicity was detected associated with the south-flowing ice stream. Notice the locations of the precursor (1) and the culminating event (2) that occurs a few minutes after. The 2006 SMOGIS array is about $50 \mathrm{~km}$ north of the ice stream. Image from Landsat Thematic Mapper (July 2001).

even at the shortest periods indicates that, for the purpose of modeling, the effect of the path can be simulated with a 1-D model of an ice layer of constant thickness over rock. Several of the models that were run included the deep graben under Jakobshavn. For sources located at the northern margin, the effect of the local geology at the distant array was found to be second order to the ringing produced by the ice waveguide.

\section{Synthetic seismograms and event magnitude}

Full-wave synthetic seismograms for the earthquake-like events within the rumblings were computed using the threedimensional (3-D) seismic wave solver e3d developed at Lawrence Livermore National Laboratory, Livermore, CA, USA (Larsen and others, 1998). Synthetics for a large range of possible focal mechanisms and radiation patterns were examined using velocity models with and without the surface ice layer. In this way, we deduced that the surface ice layer (and not complexities at the source) strongly contributes to the strong ringing seen in the P-waveforms. Although the focal mechanisms of the seismic events cannot be tightly constrained because station locations cover only an angle of $20^{\circ}$ measured from the source area, the preferred model closely reproduces the observed variation in absolute and relative amplitude of the $\mathrm{P}$ - and S-waves (Fig. 5). Fortunately, all events are almost due south from the array, which makes the SV and SH component phases (vertically and horizontally polarized $S$-waves respectively) nearly decoupled, facilitating the visual inspection of the radiation pattern and decisions on what sort of models should best represent the source. The most important observation in this regard is that the $\mathrm{SH}, \mathrm{SV}$ and P-wave radiation from the events is what would be expected from double-couple shear rupture mechanisms of ordinary earthquakes, not from single force sources or ice sliding (Ekström, 2006). Focal depths varying between $3 \mathrm{~km}$ and the surface were simulated. The closest simulation of depth phases indicates a focal depth of $1.5 \pm 0.5 \mathrm{~km}$. 


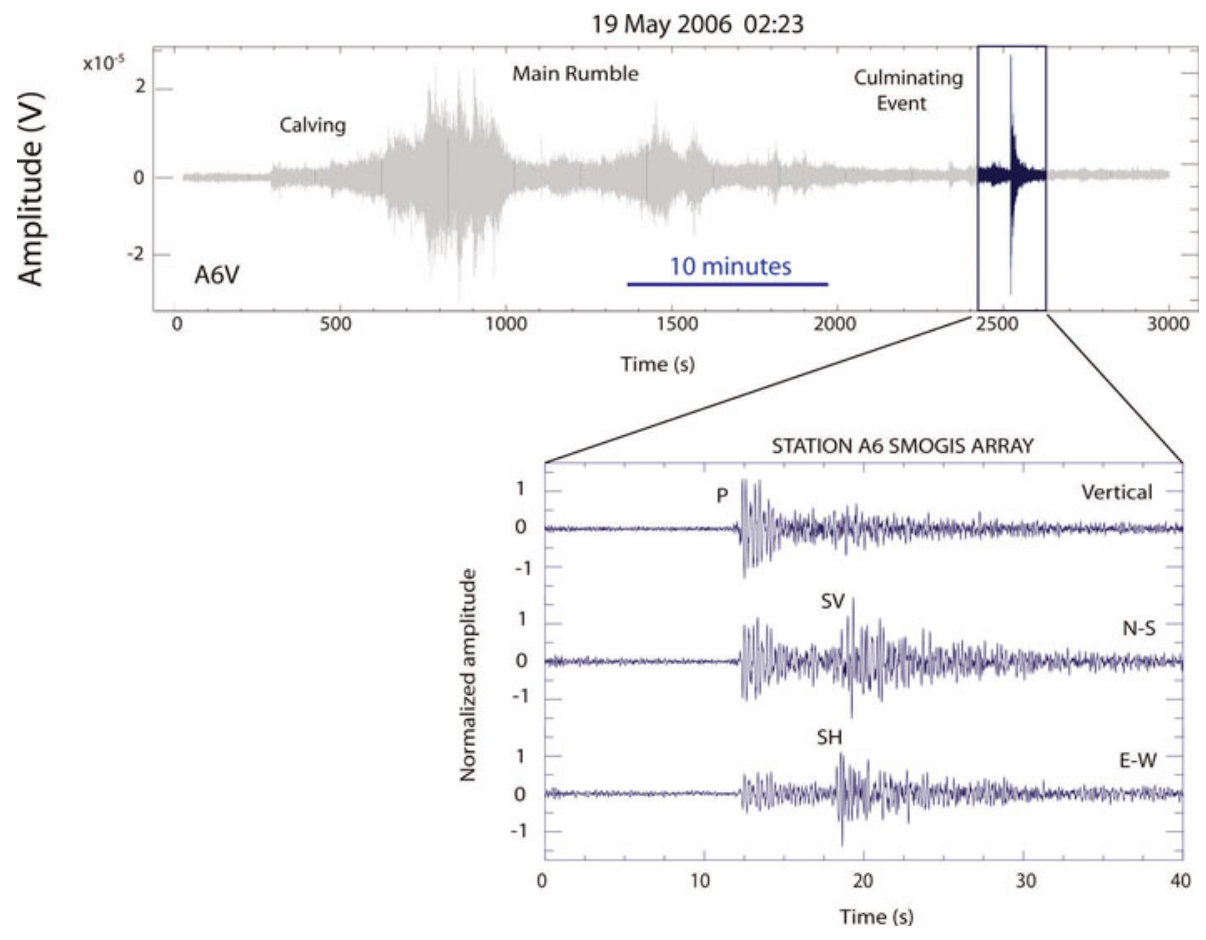

Fig. 3. Detail of the culminating event from the 19 May 2006 rumble. The inset shows an expanded view with the three components of ground motion. The seismograms show seismic wave amplitudes and phases no different from that of an ordinary earthquake produced by shear rupture. Typically, the earthquakes whose epicenters are shown in Figure 2 have similar strong P, SV and SH radiation, consistent with a double-couple mechanism. In fact, numerical experiments show that a single force mechanism oriented nearly east-west (E-W), as previously proposed, would produce strong $\mathrm{SH}$ in the $\mathrm{E}-\mathrm{W}$ component, but very small $\mathrm{P}$ and SV in the north-south $(\mathrm{N}-\mathrm{S})$ component, and almost no P on the vertical component (both P and SV phases are nearly nodal), which is not borne out by the observations at this or at other stations (see synthetic seismograms in Fig. 5).

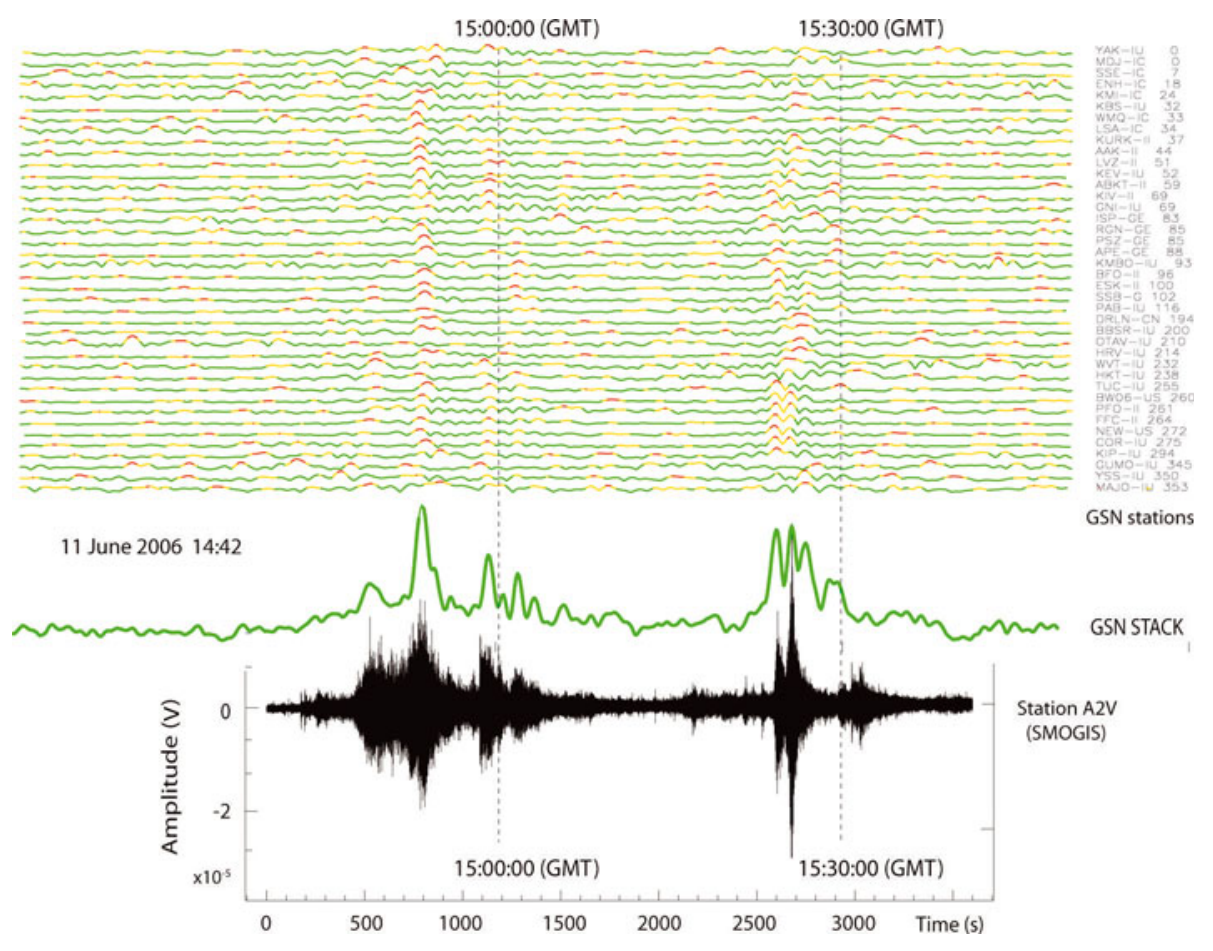

Fig. 4. Relationship between rumblings and glacial earthquakes. The figure shows the only rumbling event (11 June 2006) detected simultaneously by the GSN and the SMOGIS array. Signals from 40 GSN stations are shifted in time and stacked to enhance the originally weak signal. The resulting stack closely matches the SMOGIS recording of the event, showing the relationship between glacial earthquakes (individual peaks in the stack) and the rumbling as defined here. Stack provided by M. Nettles (see also Ekström, 2006). 
Table 1. Hypocentral locations of ice-stream events. err $X$, err $Y$, err $Z$ and err $T$ are estimated errors

\begin{tabular}{|c|c|c|c|c|c|c|c|c|c|c|c|c|}
\hline \multirow[t]{2}{*}{ Year } & Month & Day & $\mathrm{h}$ & $\min$ & $\mathrm{s}$ & Lat. & Long. & Depth & $\operatorname{err} X$ & $\operatorname{err} Y$ & $\operatorname{err} Z$ & err $T$ \\
\hline & & & & & & $\circ$ & 。 & & km & km & km & $\mathrm{s}$ \\
\hline
\end{tabular}

\begin{tabular}{|c|c|c|c|c|c|c|c|c|c|c|c|c|}
\hline \multicolumn{13}{|c|}{ Only P-waves available } \\
\hline 2006 & 05 & 14 & 05 & 59 & 13.11 & 69.3445 & -49.2955 & 2.61 & 4.53 & 6.55 & 6.04 & 1.11 \\
\hline 2006 & 05 & 14 & 20 & 09 & 51.82 & 69.3514 & -49.0589 & -0.48 & 6.48 & 4.05 & 6.90 & 1.87 \\
\hline 2006 & 05 & 14 & 20 & 11 & 04.68 & 69.5004 & -49.4383 & 3.11 & 6.66 & 6.23 & 7.07 & 1.16 \\
\hline 2006 & 05 & 19 & 10 & 18 & 17.24 & 69.2851 & -49.2283 & 4.57 & 1.47 & 0.58 & 1.27 & 0.25 \\
\hline 2006 & 05 & 27 & 23 & 12 & 49.52 & 69.1395 & -49.4446 & 2.98 & 0.56 & 0.51 & 0.58 & 0.10 \\
\hline 2006 & 06 & 01 & 05 & 44 & 14.52 & 69.1131 & -49.3633 & 2.82 & 1.48 & 1.33 & 1.52 & 0.25 \\
\hline 2006 & 06 & 01 & 08 & 01 & 29.12 & 69.0900 & -49.4365 & 3.07 & 0.98 & 0.92 & 1.00 & 0.16 \\
\hline 2006 & 06 & 06 & 20 & 48 & 47.85 & 69.1730 & -49.4720 & 2.47 & 1.30 & 1.20 & 1.39 & 0.23 \\
\hline 2006 & 06 & 08 & 04 & 28 & 04.02 & 69.1071 & -49.3323 & 3.07 & 1.72 & 1.59 & 1.75 & 0.29 \\
\hline 2006 & 06 & 09 & 00 & 57 & 29.20 & 69.1286 & -49.3142 & 2.76 & 2.03 & 1.73 & 2.09 & 0.34 \\
\hline 2006 & 06 & 09 & 09 & 46 & 21.73 & 69.0963 & -49.3861 & 2.91 & 0.50 & 0.47 & 0.52 & 0.08 \\
\hline 2006 & 06 & 09 & 09 & 57 & 07.20 & 69.0798 & -49.4039 & 2.78 & 1.86 & 1.74 & 1.90 & 0.31 \\
\hline 2006 & 06 & 11 & 14 & 58 & 51.25 & 69.0574 & -49.3698 & 2.95 & 1.25 & 1.19 & 1.27 & 0.21 \\
\hline 2006 & 06 & 11 & 15 & 22 & 11.72 & 69.3964 & -49.4514 & $1.88^{*}$ & 0.00 & 0.00 & 0.00 & 0.00 \\
\hline 2006 & 06 & 11 & 15 & 22 & 57.57 & 69.3333 & -49.1862 & $3.00 *$ & 0.00 & 0.00 & 0.00 & 0.00 \\
\hline 2006 & 06 & 11 & 15 & 31 & 09.86 & 69.0877 & -49.3476 & 2.57 & 6.48 & 6.12 & 6.60 & 1.09 \\
\hline 2006 & 06 & 12 & 04 & 18 & 17.35 & 69.1192 & -49.3956 & 3.00 & 1.18 & 1.07 & 1.22 & 0.20 \\
\hline 2006 & 06 & 12 & 07 & 12 & 46.53 & 69.1870 & -49.3460 & 3.00 & 0.58 & 0.52 & 0.60 & 0.10 \\
\hline 2006 & 06 & 12 & 11 & 38 & 39.19 & 69.1885 & -49.5391 & 7.87 & 0.60 & 0.58 & 0.64 & 0.10 \\
\hline \multicolumn{13}{|c|}{ P- and S-waves } \\
\hline 2006 & 05 & 14 & 12 & 41 & 41.67 & 69.1474 & -49.5121 & 2.94 & 1.89 & 2.19 & 2.74 & 0.30 \\
\hline 2006 & 05 & 14 & 20 & 11 & 32.52 & 69.1215 & -49.3696 & 3.00 & 1.14 & 1.37 & 1.78 & 0.19 \\
\hline 2006 & 05 & 19 & 02 & 28 & 26.72 & 69.1211 & -49.3740 & 2.80 & 0.54 & 0.90 & 1.44 & 0.11 \\
\hline 2006 & 05 & 19 & 02 & 59 & 30.69 & 69.1186 & -49.5195 & 2.50 & 0.74 & 1.05 & 1.56 & 0.13 \\
\hline 2006 & 05 & 19 & 03 & 02 & 36.50 & 69.1077 & -49.3763 & 3.07 & 0.31 & 0.52 & 0.78 & 0.06 \\
\hline 2006 & 06 & 01 & 05 & 08 & 05.05 & 69.1101 & -49.4366 & 4.61 & 2.02 & 3.00 & 4.15 & 0.39 \\
\hline 2006 & 06 & 01 & 05 & 36 & 19.62 & 69.1208 & -49.4396 & 2.46 & 1.22 & 1.83 & 2.25 & 0.22 \\
\hline 2006 & 06 & 01 & 20 & 06 & 48.71 & 69.1376 & -49.4470 & 3.00 & 0.34 & 0.37 & 0.51 & 0.05 \\
\hline 2006 & 06 & 06 & 15 & 47 & 17.21 & 69.1179 & -49.5435 & 2.81 & 1.10 & 1.43 & 2.11 & 0.17 \\
\hline 2006 & 06 & 08 & 06 & 30 & 27.06 & 69.1137 & -49.5696 & 2.91 & 0.30 & 0.36 & 0.51 & 0.05 \\
\hline 2006 & 06 & 09 & 01 & 05 & 45.90 & 69.1182 & -49.3930 & 2.99 & 1.58 & 2.45 & 3.69 & 0.29 \\
\hline 2006 & 06 & 11 & 14 & 51 & 20.91 & 69.1151 & -49.3485 & 2.96 & 0.32 & 0.53 & 0.82 & 0.06 \\
\hline 2006 & 06 & 11 & 15 & 17 & 01.31 & 69.1129 & -49.3519 & 2.91 & 0.57 & 0.92 & 1.41 & 0.11 \\
\hline 2006 & 06 & 12 & 14 & 24 & 13.31 & 69.1576 & -49.4547 & 4.98 & 1.46 & 1.63 & 2.66 & 0.20 \\
\hline
\end{tabular}

*Only three stations recorded these events.

Note: The two events in boldface belong to the same rumbling. Their timing and the location of the second upstream from the first suggests upstream propagation.

To calculate the seismic moment magnitude, we compare the amplitude of the synthetic seismogram (computed for a total moment $M_{0}$ of $10^{27}$ dyn $\mathrm{cm}$ ) with that of the observed, and then apply the empirical formula (Stein and Wysession, 2003)

$$
M_{\mathrm{W}}=\frac{\log M_{0}}{1.5}-10.73
$$

followed by averaging the values thus obtained over the array. Tectonic seismic events, with local magnitudes 2-3.5, were located some 140-160 km west and southwest of the array, a region not covered by the present ice sheet. Most of these earthquakes occur in bursts or swarms lasting a few days, with epicenters aligned near and roughly parallel to the estimated western margin of the ice sheet during the Last Glacial Maximum (Dietrich and others, 2005). They are thus likely to be related to postglacial rebound, possibly to extensional tectonics caused by deglaciation flexure at the fore-bulge of the ice sheet (Chung and Gao, 1997). Other glacial earthquakes, which we refer to as icequakes, are relatively common in the area but very small, so that more than three array stations rarely record the same event. Their characteristic strong surface waves and weak P- and S-waves closely resemble the classic Lamb's problem solution (Lamb, 1904): a seismogram produced by a single, shallow (within $100 \mathrm{~m}$ of the surface) point force in a semi-infinite halfspace, which suggests thermally induced cracks in the ice. Their estimated local magnitudes are in the range $0-1$.

\section{RUMBLING, CALVING AND EVIDENCE FOR UPSTREAM PROPAGATION}

An important clue to the nature of the rumbling process was obtained from the major rumbling of 19 May 2006 (Fig. 1, middle seismogram). We timed and located both an apparent 'precursor' (labeled 1 in Figs 1a and 2) to the culminating event and the culminating event itself. This is the only instance of two consecutive, well-located events occurring within a rumbling. The first (and smaller) of the two events occurred $125 \mathrm{~s}$ before the culminating event and 

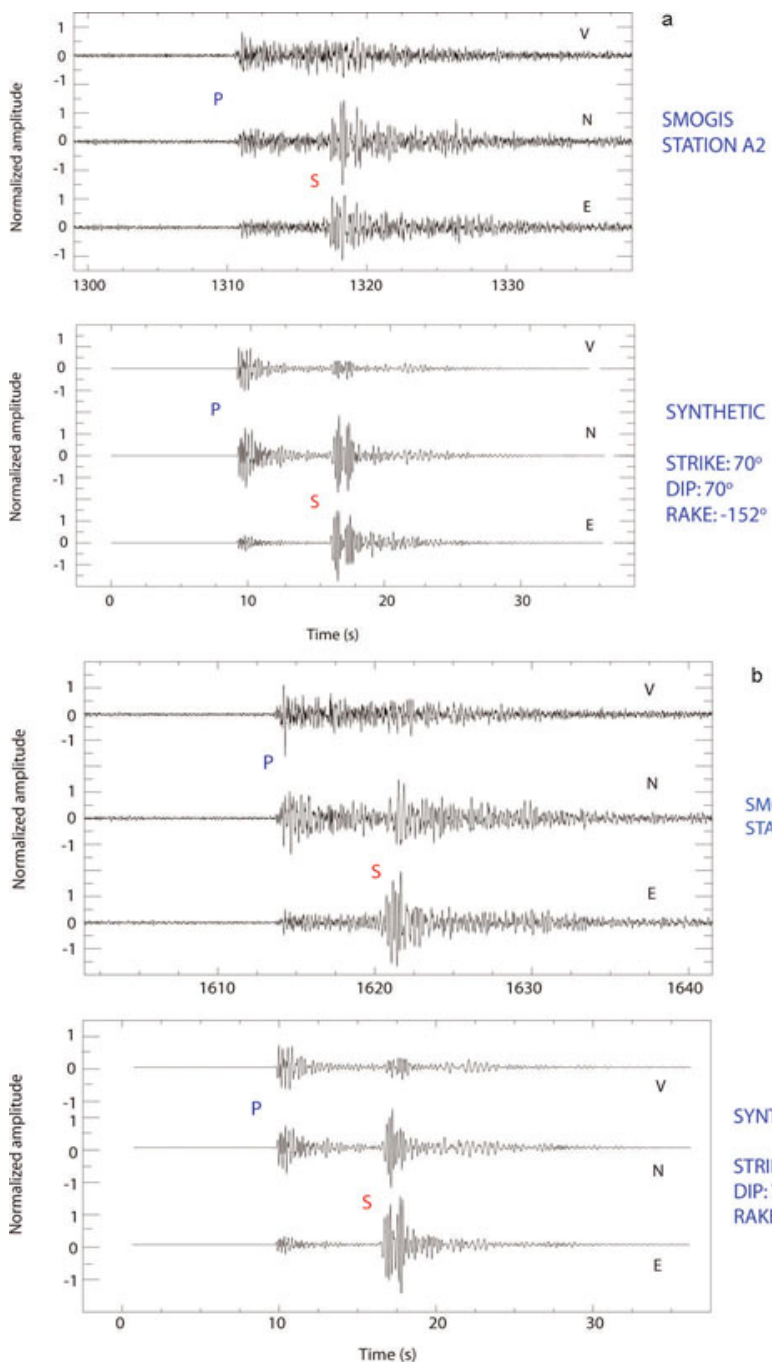

SYNTHETIC STRIKE: $70^{\circ}$ DIP: $70^{\circ}$ RAKE:-152
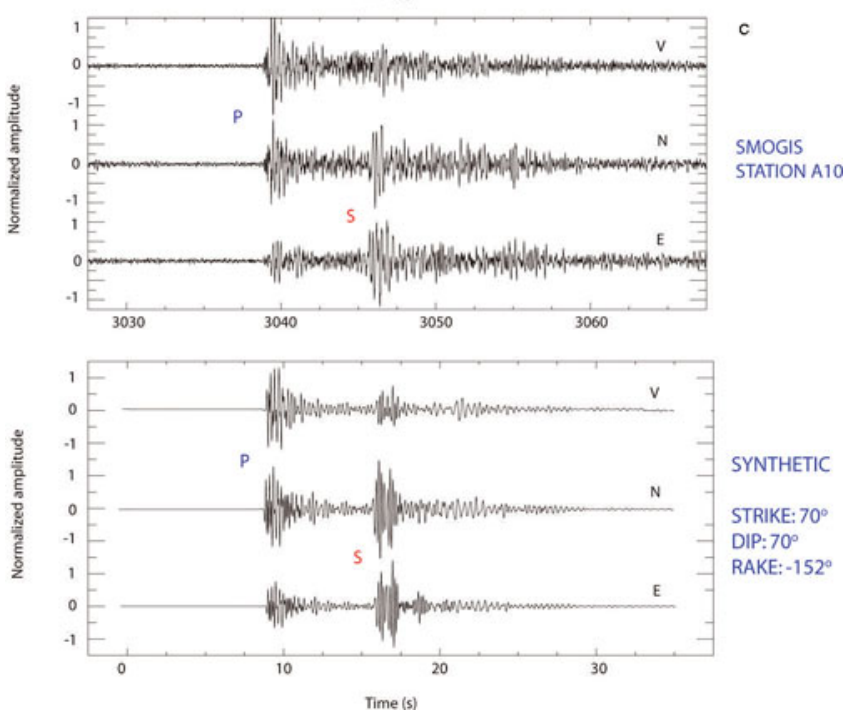

Fig. 5. Comparison between recorded and computed seismograms for the culminating event of the 19 May 2006 glacial rumbling. The synthetic is calculated for a fault consistent with the geometry of the ice-stream margin and the inclination of the deep valley's rock wall. The seismic event is interpreted as nearly horizontal slippage on a nearly vertical rupture surface on the north margin of the trough along which the ice stream flows. The focal depth is estimated at $1.5 \pm 0.5 \mathrm{~km}$. Synthetics are robust to small (5-10\%) changes in source parameters. The radiation pattern is inconsistent with a single force mechanism (see text for details). The vertical (V), northsouth (N) and east-west (E) components of ground motion are depicted in each panel. was located $5.2 \pm 1.3 \mathrm{~km}$ upstream of the calving front and $5.8 \pm 1.9 \mathrm{~km}$ downstream $(6.9 \mathrm{~km}$ if measured along the ice stream) of the epicenter of the culminating event (Fig. 2). The timing and relative locations seem to indicate that the fracturing process propagates upstream, perhaps starting at the calving front, as the observations reported below indicate. In fact, a glaciological research station deployed by researchers from the University of Alaska in the close neighborhood of Jakobshavn's terminus recorded a powerful calving event around the time of the 11 June 2006 rumbling (personal communication from J. Amundson and M. Truffer, 2007) but the exact time was not available. In 2007, Amundson and Truffer recorded calving events both photographically (time-lapse imagery) and seismically in the neighborhood of the calving front. Fortunately, four stations of the SMOGIS array were also running during 2007, and one rumbling that was recorded by a seismometer located in the rock outcrop near the southern end of the calving front allowed direct comparison of waveforms and differential arrival times with the SMOGIS deployment (Fig. 6). The origin time of the rumbling was estimated with four stations as $14 \mathrm{~h}$ : $07 \mathrm{~min}: 59.42 \pm 0.47 \mathrm{~s}$ (sampling rate $0.01 \mathrm{~s}$ ), using previously determined P-wave phase velocity through the array and assuming the calving event started at the center of the calving front. The observed arrival time at the University of Alaska calving front station (JAKO) was approximately $14 \mathrm{~h}: 07 \mathrm{~min}: 55 \pm 7.5 \mathrm{~s}$ (sampling rate $15 \mathrm{~s}$ ). Despite the low sampling rate at this station, the close timing and strong similarity in waveforms (Fig. 6) indicate that the calving event recorded at JAKO is the same as that recorded by the four SMOGIS stations as the first arrival of this rumbling. This rumbling also shows a clear culminating event that we were able to locate $12.0 \pm 5.5 \mathrm{~km}$ upstream from the calving front, with origin time $14 \mathrm{~h}: 54 \mathrm{~min}: 39.5 \mathrm{~s}$, or $46 \mathrm{~min} 40 \mathrm{~s}$ after the start of the calving event. Although the location error is large, the implication is that the rupture does migrate up-stream.

Table 2 lists University of Alaska observations of calving events in 2007 compared with arrival times of rumblings detected by the SMOGIS array. Although the observed calving times are based on time-lapse imagery and not on seismic data, and not all calving events appear to be related to rumblings, all detected rumblings occurred following or within the hour when calving observations are reported.

\section{Rumbling characteristics and dynamic interpretation}

The most important feature of the rumblings is that they are very similar to each other despite their different durations (Fig. 1). This suggests that a common dynamic, i.e. a common process (mass wasting, sliding), always occurs through the same sequence of events, from calving to culmination. This sort of timescale-invariant pattern in such a complex time series is unusual, and probably indicates a highly repeatable process of local glacier dynamics currently unknown to us. The synchrony of a large calving event with the timing of rumblings (discussed above) and the apparent synchrony shown in Table 2, suggests that calving at the glacier's terminus produces the nearly constant, small-amplitude, emergent signal that initiates the rumblings and lasts for several minutes (Fig. 1). We also have evidence that, in at least two instances, a time sequence of events in a rumbling indicates upstream propagation of the rupture process within a rumbling. 

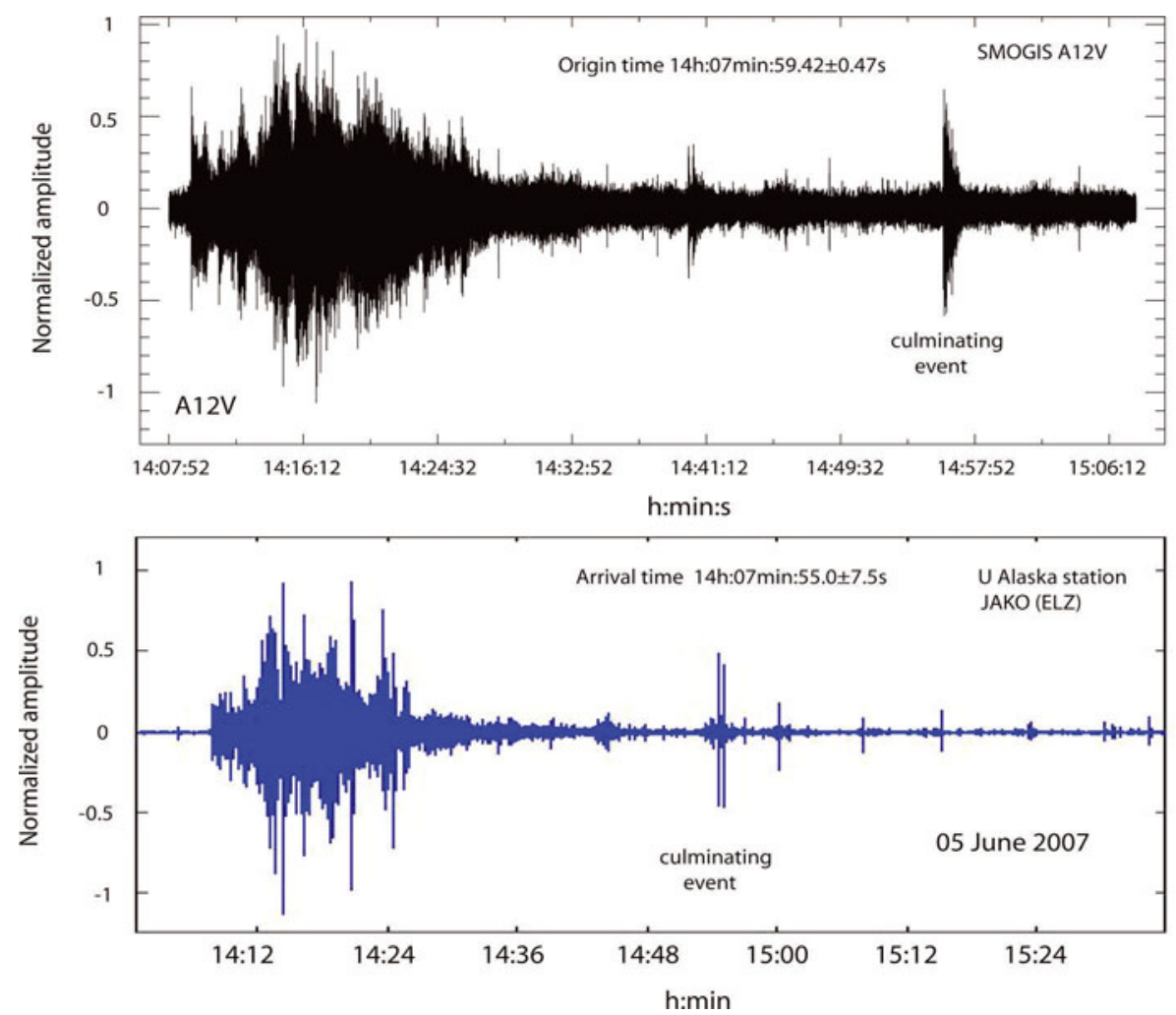

Fig. 6. Rumble of 5 June 2007 recorded at four stations of the SMOGIS array and at a calving-front seismic station (JAKO) and lapse-time photography station deployed by the University of Alaska (personal communication from J. Amundson, 2007). The calving event was detected throughout the four stations of the 2007 SMOGIS array. Origin time calculation of the calving event and the timing and location of the culminating event suggest upstream propagation of the rupture process (see text for details).

Table 2. Observed calving events and the timing of rumblings, 2007. Cm: culminating event; No signal: no rumble detected; Rumble: longduration seismic event (10-40 min)

\begin{tabular}{|c|c|c|c|}
\hline Large calving event time (UT)* & $\begin{array}{l}\text { Rumblings } \\
\text { origin time (UT) }\end{array}$ & Other phases & Remarks \\
\hline month/day/year h:min & h:min:s & & \\
\hline 5/16/07 17:00 & No data available & & \\
\hline 5/21/07 17:00 & $16: 32: 53.945$ & 16:57:07.000 (Cm) & \\
\hline 5/29/07 14:00 & 14:04:54.035 & Calving 10 s prior & \\
\hline 6/05/07 09:00 & 09:15:00.265 & 09:12:35 calving? & \\
\hline 6/05/07 13:00 & 13:12:06.935 & & Small event \\
\hline 6/05/07 14:00 & 14:07:59.42 & $14: 07: 55 \pm 7.5^{\dagger}$ & \\
\hline 6/20/07 05:00 & $05: 33: 16.015$ & 05:37:20.460 (Cm) & \\
\hline 6/20/07 20:00 & No signal & & \\
\hline 6/27/07 15:00 & $15: 07: 33.205$ & 15:09:15.205 Strong & Begin at 15:05:12.110 \\
\hline 6/29/07 07:00 & No signal & $05: 49: 49.440$ & \\
\hline 7/03/07 21:00 & 20:59:05.695 & & $\mathrm{Cm} ?$ \\
\hline 7/04/07 17:00 & $17: 21: 36.895$ & & Small rumble \\
\hline 7/10/07 07:00 & 06:47:17.705 Rumble & 07:22:18.355 Small & \\
\hline 7/14/07 09:00 & 09:05:01.485 Rumble & 09:10:17.215 (Cm) & \\
\hline 7/16/07 12:00 & No signal & 11:02:01.455 (?) & \\
\hline 7/17/07 17:00 & No signal & & \\
\hline 7/26/07 19:00 & 18:56:05.395 & & Small rumble \\
\hline 7/30/07 12:00 & $12: 07: 46.355$ & & Small rumble \\
\hline 8/01/07 20:00 & 20:35:11.065 & & Large rumble \\
\hline 8/02/07 20:00 & 19:39:33.815 Large & 19:54:30 (Cm) & \\
\hline 8/17/07 12:30 & $12: 42: 09.675$ & & Small rumble \\
\hline
\end{tabular}

*From time-lapse imagery (personal communication from J. Amundson, 2007; see also Amundson and others, 2008).

"From a seismogram recorded on land in the immediate vicinity of the calving front. 
However, without direct observation of source directivity or systematic seismicity migration we have to wait for further observations. An array closer to Jakobshavn, which is to be deployed in 2010, will help decide this important matter.

To explain the ubiquitous presence of the culminating event in all the rumblings detected, we hypothesize that as the effect of calving propagates upstream, the fractured and dislodged ice eventually undermines support (buttressing) to large ice masses upstream (the longer the rumble duration, the larger the mass to be displaced). Accelerated by the force differential created by the disappearing support, the dislodged ice slips seismically along the contact between the ice and the wall rock of the U-shaped deep glacial trough (Clarke and Echelmeyer, 1996) that underlies the ice stream. Synthetic seismograms and the radiation pattern from the events studied suggest that the seismogenic slippage that produces the culminating events occurs along the margin of the ice stream, and could be produced by a large mass-wasting event. These culminating events usually have the largest amplitude in the seismogram and, in characteristic fashion, occur at the end of the rumbling, as if marking the end of the process. Their radiated seismic energy is almost equally distributed between the P-, SV- and $\mathrm{SH}$-waves, as would be produced, for instance, by a strikeslip earthquake on a vertical or near-vertical fault oriented along the ice-stream margin. Models with a horizontal or nearly horizontal fault plane and horizontal slip vector, as would be expected from basal slip, produce $|\mathrm{SV} / \mathrm{SH}|$ amplitude ratios smaller than observed.

The best-recorded culminating event is that of 19 May 2006 (Fig. 1a). At its epicenter, the ice-stream margin is oriented $70^{\circ}$ from north, and the slope of the trough wall in this locality is $60-70^{\circ}$ (Clarke and Echelmeyer, 1996). These facts were used to approximate the geometry of the rupture surface and construct synthetic seismograms for the event. A model consistent with the observed seismic radiation pattern at the array is a fault with strike $70 \pm 5^{\circ}$ from north, dip $70 \pm 10^{\circ}$ south and rake $-152 \pm 5^{\circ}$. The best-fitting synthetic seismograms (Fig. 5) occur for a focal depth of $1.5 \pm 0.5 \mathrm{~km}$ below the surface. The synthetic seismograms of our preferred model are robust to small $(5-10 \%)$ changes in the source parameters. No attempt was made quantitatively to describe the difference between observed and computed seismograms, as high-frequency differences would bias and probably overwhelm the more important similarities in the overall amplitudes. The array elements are narrow-band, high-frequency seismometers, so low-pass filtering of the signal is hardly practicable as the response of the sensors drops rapidly below the peak at $4 \mathrm{~Hz}$.

The synthetic seismograms provide evidence of a radiation pattern consistent with a double-couple mechanism, not with a single force representing a sliding process, as proposed by Ekström and others (2003). This discrepancy is not entirely surprising, given that the teleseismic data consist of long-period surface waves in the 30-150s band whereas the culminating events recorded by our array last 10-12 s (Fig. 3), have spectral power in the $1-10 \mathrm{~Hz}$ band, and do not necessarily reflect the mechanics of the entire rumbling. There is also the fact that the centroid moment tensor (CMT) inversion scheme (Dziewonski and others, 1981) normally used to determine focal mechanisms from teleseismic long-period surface waves cannot deal with shallow, horizontal, fracture plane sources because the important moment components necessary for the double-couple description of the source vanish as the source approaches the free surface (Dahlen, 1993). To avoid this problem, Tsai and Ekström (2007) used the more appropriate centroid single-force scheme (Kawakatsu, 1989), which provides more satisfactory fits to the data. Their success in fitting the teleseismic waveforms suggests that a rumbling, if considered as a whole single event, can be in part described as a slide. However, the details we see are more complicated. Our closer look reveals that the typical duration of rumblings is much longer than $150 \mathrm{~s}$, that sliding might not actually be the entire story, and that stick-slip earthquake-like rupture along steeply dipping faults might occur in individual events within the rumblings that were not (and probably cannot be) detected teleseismically.

The dynamics of the source mechanism suggested by our data are consistent with the fact that the most accurately located events (Fig. 2) occur along the high-shear margin of the west-moving ice stream. Here, the relative motion between the streaming ice and the ice sheet is nearly $20 \mathrm{~m} \mathrm{~d}^{-1}$ (Joughin and others, 2004) so that ice is likely to fail by brittle fracture (Hooke, 2005) near the contact with the wall of the trough. The focal mechanism we prefer for the 19 May 2006 culminating event (strike $70^{\circ}$, dip $70^{\circ} \mathrm{S}$, rake $-152^{\circ}$ ) is consistent with the orientation of the icestream margin at the epicenter, the geometry and steepness of the deep valley walls. The slip vector direction, obtained from comparison with the simulated seismograms, is consistent with a combination of horizontal flow and gravity collapse, which seems kinematically reasonable. A combination of rock and ice brittle rupture cannot be ruled out, because the rupture process is certainly complex, as can be inferred from the intricate P-wave radiation; however, the details are yet to be analyzed. Synthetic seismogram experiments suggest that the culminating events must occur at depths of $1.0-2.0 \mathrm{~km}$. A likely area for the nucleation of slip is on the margin of the ice stream, about halfway to the bottom of the deep valley, where the ice temperature is $-20^{\circ} \mathrm{C}$ or below (Iken and others, 1993; Funk and others, 1994), and shear rupture similar to that in ordinary earthquakes is possible.

Basal sliding at the bottom of Jakobshavn valley might be difficult to sustain in a temperate layer. However, Anandakrishnan and others (1993) and Wiens and others (2008), among others, show that in Antarctic ice streams basal stickslip is possible, an example being 'Ice Rise $A^{\prime}$ ', a natural topographic high at the base of Whillans Ice Stream, which acts as an earthquake asperity zone. In the much narrower and steeper glacial valley under Jakobshavn ice stream, where flow processes are likely to differ from the Antarctica model, this might not happen in the same fashion. However, Wiens and others (2008) report slip episodes of $\sim 25 \mathrm{~min}$ in Antarctica, in line with the 10-40 min duration of the rumblings reported here and in contrast with the 30-150 s sources described by Ekström and others (2005).

Overall, the data show a weak linear relationship between rumble duration and maximum amplitude; that is, longer rumbles result in larger culminating events. This is consistent with the idea that longer rumbles imply greater loss of mechanical restraint (buttressing), leading to the collapse of correspondingly greater ice masses upstream. The culminating events are key to understanding the underlying mechanism, and further study of their source geometry and dynamics is clearly needed. 


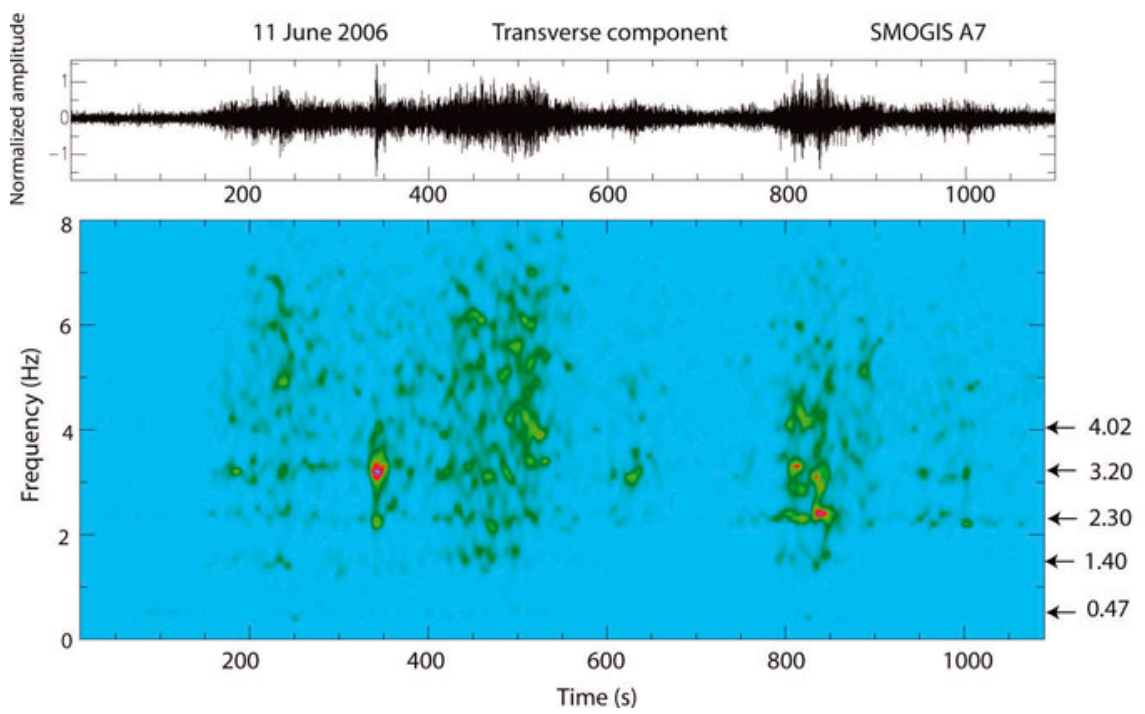

Fig. 7. Spectrogram of a section of the rumbling of 11 June 2006 showing that the transverse component (horizontally polarized S-waves, or $\mathrm{SH}$ ) includes a set of discrete frequencies consistent with the resonant modes of a layer of ice $1 \mathrm{~km}$ thick with seismic wave velocity of $1.8 \mathrm{~km} \mathrm{~s}^{-1}$ overlying rock of much higher rigidity. The normal mode frequency, $f_{\mathrm{n}}$, for such a combination is given by $f_{\mathrm{n}}=(2 n+1) B / 4 h$, where $B$ is the wave velocity, $h$ the thickness of the ice layer and $n=0,1,2$, is an integer (Ewing and others, 1957).

The time distribution of rumbling duration (a measure of their size or magnitude) during the 96 day 2006 field season appears to follow the seasonal solar input, as do most glacial earthquakes (Tsai and Ekström, 2007). However, the two largest rumblings actually occur 10 days before the summer solstice. The observation period is also too short to show a clear correlation between the occurrence of rumbling (or the size of these rumblings) and tides, in contrast to that reported for Antarctica (e.g. Bindschadler and others, 2003; Wiens and others, 2008). On Alaska's Columbia Glacier, O'Neel and others (2003) found evidence for long-period tidal modulations of calving, although in a later paper $\left(\mathrm{O}^{\prime} \mathrm{Neel}\right.$ and others, 2007) they find no conclusive evidence for tidal or other physically motivated external forcing. The subject is by no means closed and, for Jakovshavn, requires longer, multi-year time series.

All rumblings come from the ice stream feeding the glacier from the east. No clear seismic activity was detected directly on or along the ice stream that feeds Jakobshavn from the north, perhaps because this does not flow through a deep trough.

\section{RESONANCE IN THE ICE LAYER}

What sustains the strong, high-frequency wave radiation (the rumbling proper) against internal friction losses? The P-wave attenuation factor, $Q_{\mathrm{P}}$, of ice is usually less than $\sim 1000$ for polycrystalline ice (Kuroiwa, 1964). Thus, the sustained seismic radiation could be attributed to continuous and seismogenic downhill sliding of ice. However, there is evidence that the rumbling is sustained at least in part as trapped seismic energy resonates inside the ice sheet, along the path between source and receiver. According to groundpenetrating radar measurements (personal communication from G. Catania, 2006), the thickness of the ice around SMOGIS is $\sim 1 \mathrm{~km}$ and changes little between the array and the neighborhood of the glacier $(0.8-1.3 \mathrm{~km})$. In fact, spectrograms of the transverse component of ground motion show as many as five separated single-frequency bands that last as long as the rumbling (Fig. 7). The resolution of the spectrogram demonstrates that the separation between bands is nearly constant, around $0.9 \mathrm{~Hz}$, with the lowest observed frequency at $0.47 \mathrm{~Hz}$. Such a sequence is totally consistent with the transverse $(\mathrm{SH})$ eigenfrequencies of a $1 \mathrm{~km}$ thick layer of ice with S-wave velocity of $1.8 \mathrm{~km} \mathrm{~s}^{-1}$ resting over a relatively rigid (rock) substratum (Ewing and others, 1957). Similar patterns corresponding to ice thicknesses $0.9-1.3 \mathrm{~km}$ are observed at most seismic stations (if the shear wave velocity is assumed unchanged) as the source-receiver trajectories sample different regions of the ice sheet.

\section{DISCUSSION}

The culminating events must play an important role in the mass wasting process that creates the rumblings. Most of the discrete events within the rumblings show $\mathrm{P}$ - and S-wave radiation similar to that of the culminating event and rarely, as in the case of the precursor event (Fig. 1), is the noise low enough to allow event location. The radiation pattern of the culminating events is consistent with a near-vertical strikeslip shear rupture parallel to the ice-stream margin. The radiation pattern of a horizontal fault surface, which would simulate basal slippage, is similar to that of a vertical fault (Fig. 8), although it predicts a ratio $|\mathrm{SV} / \mathrm{SH}|$ that is smaller than observed. It can, however, be argued that the array sees only $\sim 20^{\circ}$ of the radiation pattern variation, which might not be diagnostic, even if the synthetic seismograms match the relative amplitudes of the different phases across the array. Furthermore, the array is centered fortuitously on one of the nodal directions for P-and SV-waves of both source models (The azimuth to the array measured from the direction of flow is about $90^{\circ}$ ). In a glacier the basal layer of which is temperate (Funk and others, 1994), it is intuitively difficult to think of stick-slip earthquake-like slippage, yet it has been shown that such events can happen even for thawed beds (Anandakrishnan and Bentley, 1993; Wiens and others, 2008). Thus, basal slip on a horizontal fault cannot be totally ruled out at this time. 
As indicated above, the magnitude, $M_{\mathrm{W}}$, of the culminating events ranges between 4.0 and 4.3, which is smaller than the low-end value calculated with the global seismic network. The discrepancy is resolved if we estimate the magnitude of the rumblings using their entire duration. There might be a number of ways to proceed, but one we find very simple is to note that each rumbling contains a large number of individual seismic events, sometimes recognizable by their $\mathrm{P}$ - and $\mathrm{S}$-waves and by the fact their amplitude is greater than the background. In the timescale of Figure 1, these events appear as spikes distributed throughout the seismogram at irregular times and with varying amplitudes. An approximate estimate of each rumbling moment magnitude (i.e. what a teleseismic observer would measure as $M_{\mathrm{W}}$ ) can be made because variations in the actual location of the sources (as long as a rumbling is assumed to be a single process of rupture in a localized area, as appears to be the case) and the precise timing of the spikes within the rumble do not affect such a magnitude estimate. We observe that there are typically 15-25 spike-like events in a 1000s rumble (cf. Fig. 1), so we can assume that each rumble is made up of discrete events separated by $\sim 50 \mathrm{~s}$ from each other and each with the average amplitude of the spikes, which is very close to half that of the culminating event. We disregard the background wavefield, which we described above as mostly resonant energy in the ice layer and which will probably be attenuated at teleseismic distances. With such a construct we obtain a moment magnitude range of 4.6-4.9 (culminating event included) for the 10-40 min rumblings, respectively, which is consistent with the magnitudes reported by Tsai and Ekström (2007) for the Jakobshavn area and explains the discrepancy.

From these magnitude values the total seismic energy released during the 96 days of recording by the rumblings can be estimated and, from that, the total seismic moment, $M_{0}$. Then, using $M_{0}=\mu S D$ (Aki and Richards, 2002) we find that the total energy released by the rumblings is equivalent to, for example, a shear displacement, $D$, of $150 \mathrm{~m}$ over a $\sim 4 \mathrm{~km}^{2}$ rupture surface, $\mathrm{S}$ (rupture surface $2 \mathrm{~km}$ long and $2 \mathrm{~km}$ deep). This assumes that the ice rigidity, $\mu$, is $\sim 3 \times 10^{10}$ cgs units (shear wave velocity of $1.8 \mathrm{~km} \mathrm{~s}^{-1}$ ). As the ice stream is $3 \mathrm{~km}$ wide, the maximum seasonal amount of ice moved (seismogenically) down the ice stream is up to $12 \mathrm{~km}^{3}$ if its entire width slips, or $\sim 30 \%$ of the average annual iceberg discharge in Jakobshavn (Maas and others, 2006). As eight long rumblings (longer than $1000 \mathrm{~s}$ ) made the bulk of the wave radiation during the 2006 season, one simple way to collect these quantities together is to say that the maximum volume of ice displaced seismically per rumble was, for instance, $12 \mathrm{~km}^{3}$ each with seismic slip of $19 \mathrm{~m}$, or $1.5 \mathrm{~km}^{3}$ each with slip of $150 \mathrm{~m}$.

In this paper we have reported the detection of unexpected seismic events of extraordinarily long duration (10-40 min) occurring about once every 2 days during the melt season, and localized in the ice stream that feeds Jakobshavn Isbræ, Greenland's fastest-moving outlet glacier. As the process is clearly seismogenic, we argue that continuous seismic monitoring of Greenland's outlet glaciers could provide answers to whether and how the surge in seismic activity over the last decade (Ekström and others, 2006) is related to the ice sheet's response to ongoing warming.

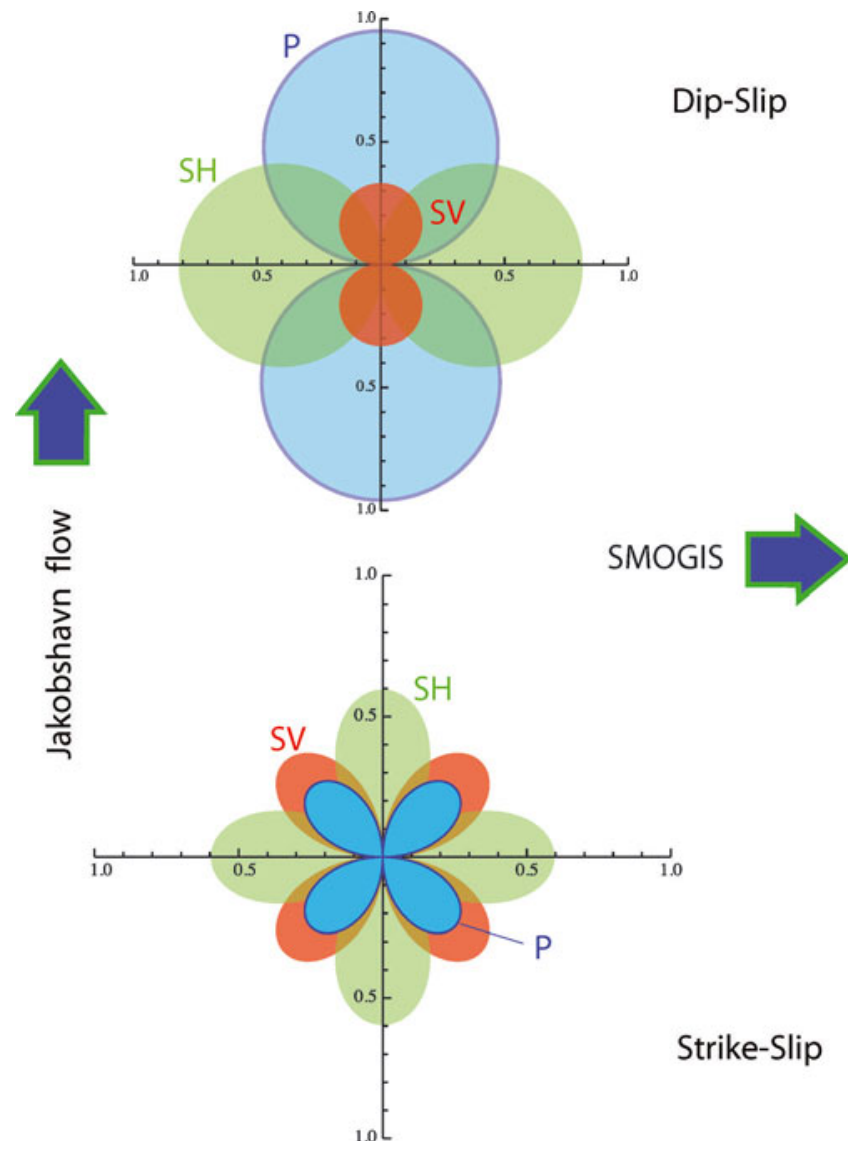

Fig. 8. Absolute amplitude $\mathrm{P}, \mathrm{SV}$ and $\mathrm{SH}$ radiation patterns for the two competing models of the culminating event double-couple source. The dip-slip mechanism is for a horizontal rupture plane with slippage along the direction of the Jakobshavn flow. The same slippage direction, but on a vertical plane strike-slip fault, produces a different radiation pattern, especially the ratio $|\mathrm{SV} / \mathrm{SH}|$. The array is in a nodal direction in both cases. The view is from above and the amplitude is for the take-off angle $\left(\sim 30^{\circ}\right)$ appropriate to the epicentral distance and velocity model.

\section{ACKNOWLEDGEMENTS}

This research was partially funded by the US National Science Foundation (Paleoclimate program) and by the US National Oceanic and Atmospheric Administration (CIRES Visiting Fellowship to J.A.R.). Useful comments by S. Anandakrishnan and two anonymous reviewers helped to greatly improve the original manuscript. We also acknowledge useful comments from R. Alley, C. Langston and M. Nettles. J. Lees provided the hypocentral determination code.

\section{REFERENCES}

Aki, K. and P.G. Richards 1980. Quantitative seismology. Second edition. Sausalito, CA, University Science Books.

Alley, R.B., M.K. Spencer and S. Anandakrishnan. 2007. Ice-sheet mass balance: assessment, attribution and prognosis. Ann. Glaciol., 46, 1-7.

Amundson, J.M., M. Truffer, M.P. Lüthi, M. Fahnestock, M. West, R.J. Motyka. 2008. Glacier, fjord and seismic response to recent large calving events, Jakobshavn Isbræ, Greenland. Geophys. Res. Lett., 35, L22501. (doi: 10.1029/2008GL035281.) 
Anandakrishnan, S. and C.R. Bentley. 1993. Micro-earthquakes beneath Ice Streams B and C, West Antarctica: observations and implications. J. Glaciol., 39(133), 455-462.

Bamber, J.L., R.B. Alley and I. Joughin. 2007. Rapid response of modern day ice sheets to external forcing. Earth Planet. Sci. Lett., 257(1-2), 1-13.

Bindschadler, R.A., M.A. King, R.B. Alley, S. Anandakrishnan and L. Padman. 2003. Tidally controlled stick-slip discharge of a West Antarctic ice stream. Science, 301(5636), 1087-1089.

Chung, W.-Y. and H. Gao. 1997. The Greenland earthquake of 11 July 1987 and postglacial fault reactivation along a passive margin. Bull. Seismol. Soc. Am., 87(4), 1058-1068.

Clarke, T.S. and K. Echelmeyer. 1996. Seismic-reflection evidence for a deep subglacial trough beneath Jakobshavns Isbræ, West Greenland. J. Glaciol., 43(141), 219-232.

Dahlen, F. A. 1993. Single-force representation of shallow landslide sources. Bull. Seismol. Soc. Am., 83(1), 130-143.

Dietrich, R., A. Rülke and M. Scheinert. 2005. Present-day vertical crustal deformations in West Greenland from repeated GPS observations. Geophys. J. Int., 163(3), 865-874.

Dziewonski, A.M., T.-A. Chou and J.H. Woodhouse. 1981. Determination of earthquake source parameters from waveform data for studies of global and regional seismicity. J. Geophys. Res., 86(B4), 2825-2852.

Ekström, G. 2006. Global detection and location of seismic sources by using surface waves. Bull. Seismol. Soc. Am., 96(4A), $1201-1212$

Ekström, G., M. Nettles and G.A. Abers. 2003. Glacial earthquakes. Science, 302(5645), 622-624.

Ekström, G., M. Nettles and V.C. Tsai. 2006. Seasonality and increasing frequency of Greenland glacial earthquakes. Science, 311(5768), 1756-1758.

Ewing, M., W. Jardetzky and F. Press 1957. Elastic waves in layered media. New York, McGraw-Hill.

Funk, M., K. Echelmeyer and A. Iken. 1994. Mechanisms of fast flow in Jakobshavns Isbræ, West Greenland: Part II. Modeling of englacial temperatures. J. Glaciol., 40(136), 569-585.

Hansen, J.E. 2005. A slippery slope: how much global warming constitutes 'dangerous anthropogenic interference'? Climatic Change, 68(3), 269-279.

Hooke, R.LeB. 2005. Principles of glacier mechanics. Second edition. Cambridge, etc., Cambridge University Press.

Howat, I.M., I. Joughin, S. Tulaczyk and S. Gogineni. 2005. Rapid retreat and acceleration of Helheim Glacier, east Greenland. Geophys. Res. Lett., 32(22), L22502. (10.1029/2005GL024737.)

Howat, I.M., I.R. Joughin and T.A. Scambos. 2007. Rapid changes in ice discharge from Greenland outlet glaciers. Science, 315(5818), 1559-1561.

Iken, A., K. Echelmeyer, W. Harrison and M. Funk. 1993. Mechanisms of fast flow in Jakobshavns Isbræ, West Greenland: Part I. Measurements of temperature and water level in deep boreholes. J. Glaciol., 39(131), 15-25.

Joughin, I., W. Abdalati and M.A. Fahnestock. 2004. Large fluctuations in speed on Greenland's Jakobshavn Isbræ glacier. Nature, 432(7017), 608-610.

Kawakatsu, H. 1989. Centroid single force inversion of seismic waves generated by landslides. J. Geophys. Res., 94(B9), $12,363-12,374$.
Kuroiwa, D. 1964. Internal friction of ice. Contrib. Inst. Low Temp. Sci. A18, 2-37.

Lamb, H. 1904. On the propagation of tremors over the surface of an elastic solid. Philos. Trans. R. Soc. London, Ser. A, 203, $1-42$.

Larsen, S., D. Harris, C. Schultz, D. Maddix, T. Bakowsky and L. Bent. 1998. E3D. 3D elastic seismic wave propagation code. Livermore, CA, Lawrence Livermore National Laboratory. (Tech. Rep. ESTSC-001300MLTPL00.)

Lawson, C.L. and R.J. Hanson 1995. Solving least squares problems. Philadelphia, PA, Society for Industrial and Applied Mathematics.

Lee, W.H.K. and S.W. Stewart 1981. Principles and applications in microearthquake networks. New York, Academic Press.

Lüthi, A., M. Funk and A. Iken. 2003. Indication of active overthrust faulting along the Holocene-Wisconsin transition in the marginal zone of Jakobshavn Isbræ. J. Geophys. Res., 108(B11), 2543. (10.1029/2003JB002505.)

Maas, H.-G., R. Dietrich, E. Schwalbe, M. Bässler and P. Westfeld. 2006. Analysis of the motion behaviour of Jakobshavn Isbræ Glacier in Greenland by monocular image sequence analysis. Int. Arch. Photogramm. Remote Sens., 36(5), 179-183.

O'Neel, S., H.P. Marshall, D.E. McNamara and W.T. Pfeffer. 2007. Seismic detection and analysis of icequakes at Columbia Glacier, Alaska. J. Geophys. Res., 112(F3), F03S23. (10.1029/ 2006JF000595.)

O'Neel, S. and W.T. Pfeffer. 2007. Source mechanics for monochromatic icequakes produced during iceberg calving at Columbia Glacier, AK. Geophys. Res. Lett., 34(22), L22502. (10.1029/2007GL031370.)

Petrenko, V.F. and R.W. Whitworth 1999. Physics of ice. Oxford, etc., Oxford University Press.

Rignot, E. and P. Kanagaratnam. 2006. Changes in the velocity structure of the Greenland Ice Sheet. Science, 311(5673), 986-990.

Stearns, L.A. and G.S. Hamilton. 2007. Thinning and acceleration of East Antarctic outlet glaciers. [Abstract C41C-08.] Eos, 88(52), Fall Meet. Suppl.

Steffen, K., S. Nghiem, R. Huff and G. Neumann. 2004. The melt anomaly of 2002 on the Greenland Ice Sheet from active and passive microwave satellite observations. Geophys. Res. Lett., 31(20), L20402. (10.1029/2004GL020444.)

Steffen, K., J.H. Zwally, J.A. Rial, A. Behar and R. Huff. 2006. Climate variability, melt-flow acceleration, and ice quakes at the western slope of the Greenland Ice Sheet. [Abstract U22A-01.] EOS, 87(52), Fall Meet. Suppl.

Stein, S. and M. Wysession 2003. Introduction to seismology, earthquakes and earth structure. Oxford, Blackwell Publishing.

Tsai, V.C. and G. Ekström. 2007. Analysis of glacial earthquakes. J. Geophys. Res., 112(F3), F03522. (10.1029/2006JF000596.)

Wiens, D.A., S. Anandakrishnan, J.P. Wineberry and M.A. King. 2008. Simultaneous teleseismic and geodetic observations of the stick-slip motion of an Antarctic ice stream. Nature, 453(7196), 770-774.

Zwally, H.J., W. Abdalati, T. Herring, K. Larson, J. Saba and K. Steffen. 2002. Surface melt-induced acceleration of Greenland ice-sheet flow. Science, 297(5579), 218-222. 